\title{
ANALISIS PENGENDALIAN KUALITAS AIR MINUM DALAM KEMASAN MENGGUNAKAN METODE SIX SIGMA
}

\author{
Wahyu Oktri Widyarto, Azirwan Firdaus, Aulia Kusumawati \\ Program Studi Teknik Industri, Fakultas Teknik, Universitas Serang Raya \\ Email:woktri@gmail.com; azirwanriyadi@gmail.com; aulia07@gmail.com
}

\begin{abstract}
Abstrak-Air minum dalam kemasan dipasarkan dengan berbagai variasi kemasan salah satunya adalah kemasan galon. Beberapa permasalahan yang terjadi pada kualitas galon adalah galon bocor, galon pecah, air kotor, body kotor dan galon berlumut. Penelitian ini bertujuan untuk menentukan performance baseline perusahaan yang dilihat dari nilai Defect Per Million Opportunities (DPMO) dan tingkat sigma, melakukan identifikasi penyebab kecacatan produk. Pembahasan yang dilakukan mengikuti langkah DMAIC pada six sigma. Berdasarkan hasil pengolahan data, dapat diketahui bahwa nilai DPMO sebesar 662,46 dan tingkat sigma sebesar 4,84. Hasil ini dapat menjadi dasar bagi perusahaan dalam upaya meningkatkan kinerja kualitas produk yang dihasilkan.
\end{abstract}

Kata kunci: DPMO, Pengendalian Kualitas, Six Sigma

\begin{abstract}
Bottled drinking water is market with a variety of packaging, one of which is gallon packaging. Some of the problems that occur in the quality of the gallon are leaky gallons, broken gallons, dirty water, dirty bodies, and mossy gallons. This study aims to determine the company's baseline performance as seen from the value of Defect Per Million Opportunities (DPMO) and sigma level, identifying the causes of product defects. Discussions were carried out following DMAIC's steps on six sigma. Based on the results of data processing, it can see that the DPMO value is 662.46, and the sigma level is 4.84 . This result can be the basis for the company to improve the performance of the quality of the products produced.
\end{abstract}

Keywords: DPMO, Quality Control, Six Sigma

\section{PENDAHULUAN}

Air minum dalam kemasan dipasarkan dengan berbagai variasi yaitu kemasan cup, botol, dan galon. Untuk mempertahankan kepercayaan pelanggan, maka perlu dilakukan upaya meningkatkan kualitas produk air minum dalam kemasan.

Kualitas pada perusahaan manufaktur dan jasa memiliki peranan penting dalam upaya untuk meningkatkan, mempertahankan, dan mendapatkan kembali pangsa pasar pada perusahaan. (Charles, Kumar, \& Suggu, 2013). Metode six sigma, dapat digunakan untuk melakukan analisis kualitas suatu produk melalui langkah Define, Measure, Analyze, Improve, Control yang sering dikenal dengan langkah DMAIC.

Beberapa penelitian telah dilakukan mengenai penggunaan six sigma dalam pengendalian kualitas. Caesaron, \& Simatupang (2015), menggunakan pendekatan DMAIC untuk perbaikan pipa PVC. Hasil dari penelitian ini yaitu terdapat penurunan kecacatan produk dan meningkatnya nilai sigma sebesar 3,97. Ghiffari, Harsono, \& Bakar (2013), menggunakan six sigma pada proses sablon dengan melakukan rancangan perbaikan standar operasional proses. Nilai sigma yang dapat dicapai yaitu 2,05 dengan DPMO sebesar 290,741. Wibisono,\& Suteja(2013), melakukan perbaikan mutu pada industri kecil menengah dengan menggunakan konsep DMAIC dan dapat memperbaiki kualitas produk. Widyarto, Dwiputra, \& Kristiantoro (2015), menerapkan metode six sigma dalam analisis kualitas produk yang berfokus pada pengendalian cacat yang dominan.

Berdasarkan latar belakang tersebut, perlu adanya analisis pengendalian kualitas pada air minum dalam kemasan khususnya kemasan galon yang diproduksi oleh PT. $X$ sebagai upaya untuk melakukan perbaikan kualitas secara terus-menerus. Hal ini dikarenakan masih terdapat produk yang tidak memenuhi spesifikasi dikarenakan adanya galon bocor, galon pecah, 
air kotor, body kotor dan galon berlumut. Penelitian ini akan membahas tentang analisis pengendalian kualitas dengan metode six sigma melalui penentuan nilai DPMO dan tingkat sigma sebagai kinerja dasar yang selanjutnya dapat dijadikan masukan dalam menentukan rencana tindakan perbaikan kualitas

\section{METODE PENELITIAN}

Penelitian ini diawali dengan studi pendahuluan yaitu observasi dan studi literatur sehingga dapat diidentifikasi masalah penelitian bersama tujuan penelitian. Pengumpulan data didasarkan pada periode permintaan 12 bulan kebelakang mengenai jumlah produksi, jumlah produk cacat, jenis dan jumlah kecacatan. Pengolahan data dilakukan dengan menggunakan metode six sigma.

Six sigma memiliki lima langkah sistematis yang terdiri dari fase Define, Measure, Analyze, Improve dan Control.

\section{a. Define}

Tahap define sebagai langkah operasional pertama dalam program peningkatan kualitas six sigma. Dalam hal ini, perlu dilakukan definisi proses-proses kunci beserta interaksinya serta pelanggan yang terakibat didalam setiap proses tersebut. Untuk mengetahui hal tersebut, perlu dibuat diagram SIPOC (Supplier-Input-ProcessOutput-Customer) yang dapat bermanfaat dalam upaya peningkatan proses. (Gaspersz, 2002).

\section{b. Measure}

Tahap Measure merupakan tahap pengukuran tingkat kecacatan dan kinerja. (Fatma, \& Lestari, 2017). Pada tahapan ini terdapat tiga hal yang perlu dilakukan yaitu: (Gaspersz, 2002)

1. Menentukan karakteristik kualitas kunci (Critical To Quality/CTQ).

CTQ merupakan karakterstik yang kritis pada usaha peningkatan kualitas. Dapat diartikan sebagai variabel yang berpotensi sebagai penyebab cacat dan penurunan grade. (Prastawa, Khoiriyah,\& Sutarso, 2005). Penetapan CTQ yang berkaitan langsung dengan kebutuhan spesifik pelanggan akan bergantung pada situasi dan kondisi organisasi bisnis tersebut baik internal maupun eksternal (Gaspersz, 2002).

2. Mengembangkan rencana pengumpulan data Pengukuran kualitas dapat dilakukan pada tiga tingkat, yaitu tingkat proses, tingkat output dan tingkat outcome. (Gaspersz, 2002).

3. Pengukuran Baseline Kinerja

Ukuran hasil kinerja baseline yang digunakan pada six sigma yaitu DPMO dan tingkat sigma. Hal ini dilakukan untuk mengetahui tingkat kinerja proses saat ini yang dapat menjadi tolak ukur dalam melakukan tindakan perbaikan, (Fatma, \& Lestari, 2017). Secara matematis, DPMO dapat dirumuskan dengan: (Gaspersz, 2002)

DPMO = Banyak produk cacat / (banyak produk yang diperiksa $x$ CTQ potensial) $x$ 1.000 .000

Nilai DPMO suatu produk akan menggambarkan rata-rat pengukuran dari suatu proses. Nilai DPMO yang diperoleh dikonversikan kedalam tingkat sigma dengan menggunakan tabel sigma. (Fatma, \& Lestari, 2017).

\section{c. Analyze}

Tahap Analyze merupakan tahap identifikasi dan menentukan penyebab suatu masalah. (Fatma, \& Lestari, 2017). Menurut Pande, Neuman, \& Cavanagh, (2003),terdapat dua sumber input dalam menentukan penyebab masalah yaitu analisis data dan analisis proses.

\section{d. Improve}

Tahap improve merupakan tahap pemberian usulan rencana tindakan perbaikan untuk melaksanakan peningkatan kualitas. (Fatma, \& Lestari, 2017). Dalam program peningkatan kualitas six sigma, rencana tindakan perbaikan dapat menjadi suatu aktivitas yang penting.

\section{e. Control}

Tahap control merupakan tahapan operasional terakhir dari six sigma. Tahap ii akan mendokumentasikan dan menyebarkan hasilhasil peningkatan kualitas, membuat standardisasi dan penyebarluasan praktekpraktek terbaik yang sukses dalam meningkatkan proses, pendokumentasian prosedur-prosedur dan dijadikan pedoman kerja standar, serta kepemilikan dan tanggungjawab ditransfer dari tim Six sigma kepada pemilik atau penanggungjawab proses. (Gaspersz, 2002).

\section{HASIL DAN PEMBAHASAN}

a. Define

1) Pernyataan Masalah

Kegiatan produksi air minum kemasan galon yang diproduksi PT. $X$ masih terdapat masalah kualitas yang tidak sesuai dengan spesifikasi yang meliputi galon berlumut, bocor, pecah, kotor, dan air kotor. Hal ini perlu dilakukan mendapatkan perhatian lebih karena berhubungan dengan kualitas dan kepuasan 
konsumen. .

2) Pernyataan Tujuan

Peningkatan kualitas produk air minum kemasan galon dan peningkatan kapabilitas proses dengan meminimalisir kecacatan produk yang terjadi sehingga kerugian dapat diatasi.
3) Diagram SIPOC

Diagram SIPOC memberikan gambaran mengenai kebutuhan proses dan persyaratan kunci beserta interaksinya (Gambar 1).

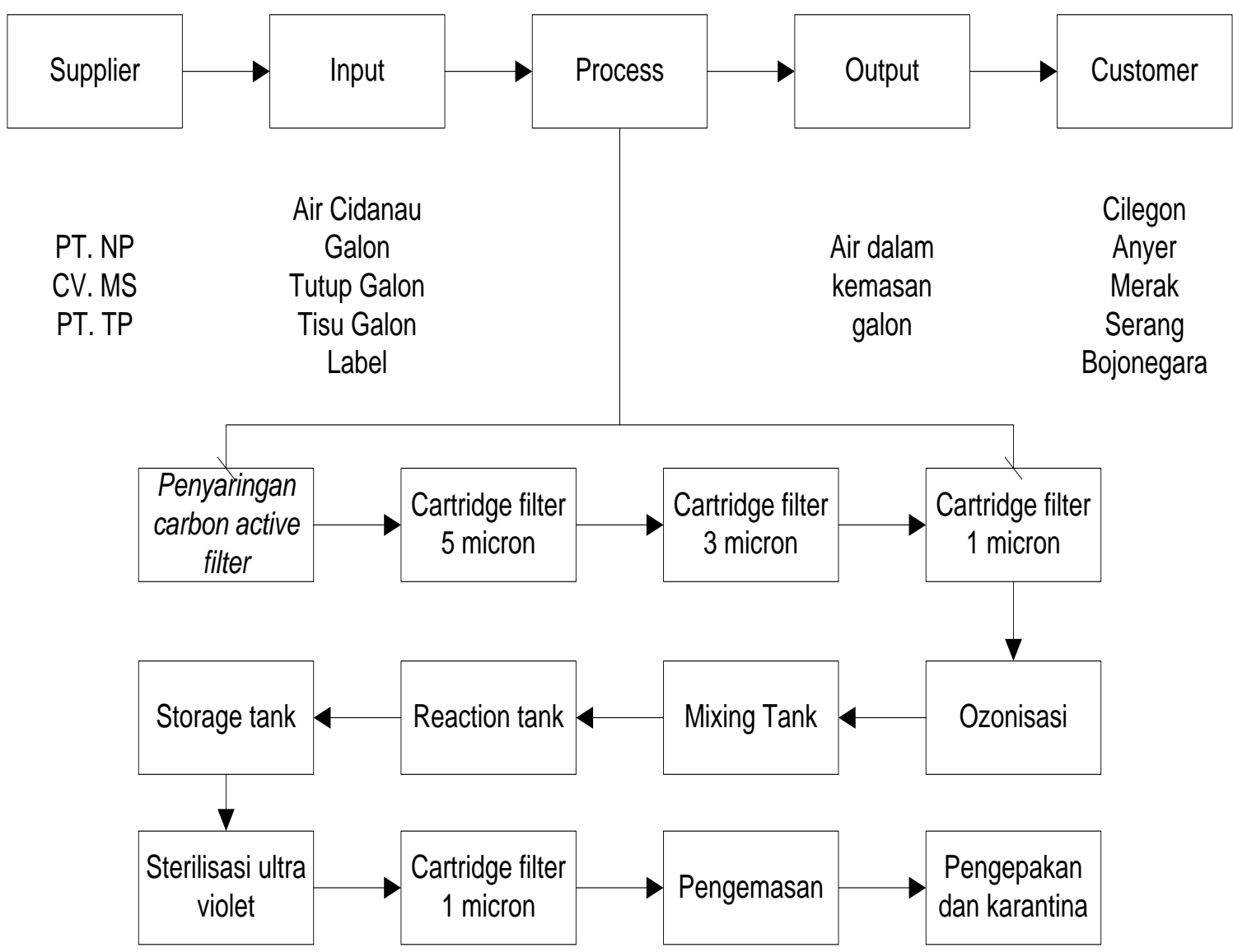

Gambar 1. Diagram SIPOC proses produksi air minum kemasan galon

b. Measure

1) Menentukan $C T Q$

CTQ pada proses produksi air minum kemasan galon ditampilkan pada tabel 1 . Berdasarkan tabel 1 diperoleh hasil bahwa galon bocor merupakan permasalahan yang paling dominan dalam masalah air minum.

Tabel 1. CTQ produksi air minum kemasan galon

\begin{tabular}{llc}
\hline No & CTQ & Jumlah (Galon) \\
\hline 1 & Galon bocor & 1488 \\
2 & Galon pecah & 445 \\
3 & Air kotor & 273 \\
4 & Body kotor & 132 \\
5 & Galon berlumut & 47 \\
\hline Jumlah & 2385 \\
\hline
\end{tabular}

2) Mengukur performance baseline

Pengukuran performance baseline dilakukan dengan menentukan nilai DPMO yang selanjutnya akan dikonversikan kedalam tingkat sigma. Tabel 2 menunjukkan perhitungan nilai DPMO dan tingkat sigma.

Dari hasil perhitungan, dapat diketahui bahwa nilai DPMO selama 12 periode yaitu sebesar 662,46, yang berarti bahwa dari sejuta kesempatan yang ada akan terdapat 662,46 kemungkinan bahwa air minum kemasan galon masih mengalami kegagalan dengan nilai sigma sebesar 4,84. Pencapaian nilai sigma ini sudah termasuk baik akan tetapi perlu ditingkatkan lagi sehingga permasalahan yang terjadi dapat diminimalkan dalam rangka peningkatan kualitas dalam rangka menjamin produk aman. 
Tabel 2. Perhitungan DPMO dan tingkat sigma

\begin{tabular}{cccccc}
\hline Periode & $\begin{array}{c}\text { Jumlah Produksi } \\
\text { (Galon) }\end{array}$ & $\begin{array}{c}\text { Jumlah Produk } \\
\text { Cacat (Galon) }\end{array}$ & CTQ & DPMO & Tingkat Sigma \\
\hline 1 & 70689 & 144 & 5 & 407,41 & 4,84 \\
2 & 68066 & 132 & 5 & 387,85 & 4,86 \\
3 & 51403 & 137 & 5 & 533,04 & 4,77 \\
4 & 56348 & 0 & 5 & 0 & 6 \\
5 & 38905 & 177 & 5 & 909,90 & 4,61 \\
6 & 67749 & 32 & 5 & 94,46 & 5,23 \\
7 & 68404 & 249 & 5 & 728,02 & 4,68 \\
8 & 64348 & 293 & 5 & 910,67 & 4,61 \\
9 & 61649 & 315 & 5 & 1021,91 & 4,58 \\
10 & 61895 & 162 & 5 & 523,46 & 4,77 \\
11 & 56837 & 444 & 5 & 1562,36 & 4,45 \\
12 & 68935 & 300 & 5 & 870,38 & 4,63 \\
\hline Rata-rata & 61269 & 198,75 & 5 & 662,46 & 4,84 \\
\hline
\end{tabular}

c. Analyze

Pada tahap ana;yze, dilakukan identifikasi penyebab kecacatan yang terjadi pada air minum kemasan galon. Alat bantu yang digunakan untuk identifikasi pada penelitian ini yaitu diagram pareto.

Berdasarkan diagram pareto pada gambar 2, fokus perbaikan dilakukan pada kecacatan galon bocor dan galon pecah.Selanjutnya, dilakukan identifikasi dengan menggunakan fishbone diagram dengan analisa galon bocor disebabkan tambalan galon retak dan operator salah memilih galon (Gambar 2). Sedangkan galon jatuh dan galon rembes merupakan faktor terjadinya galon pecah (Gambar 4)

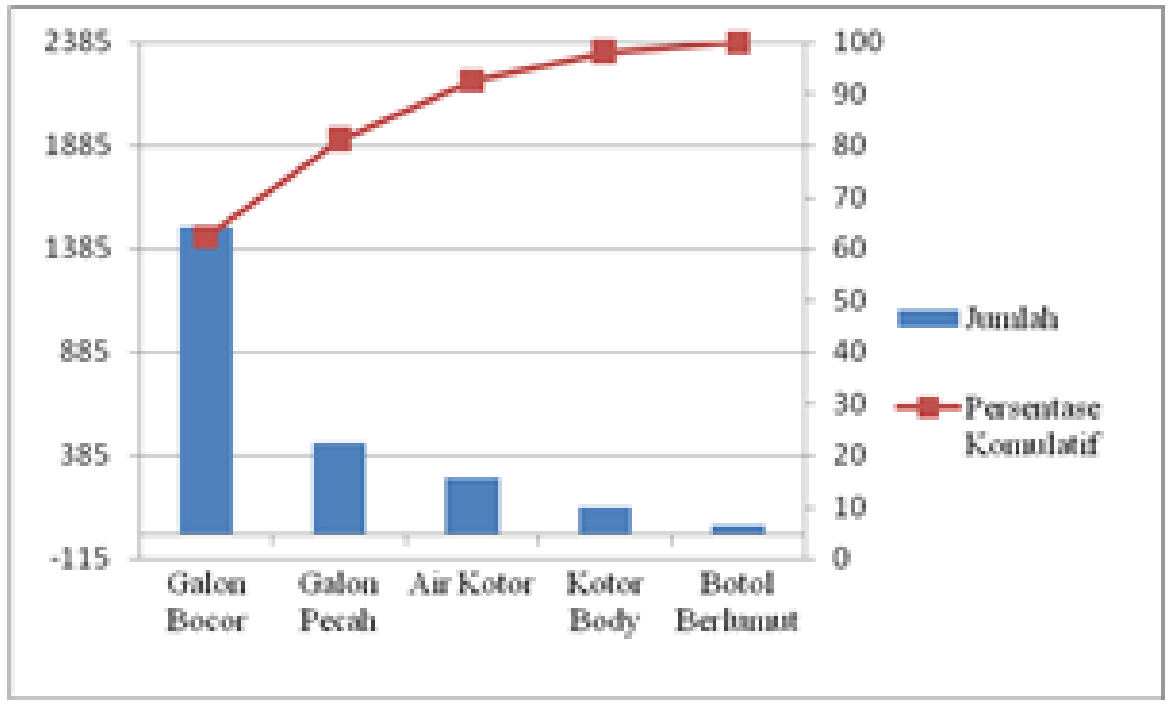

Gambar 2. Diagram pareto jenis kecacatan air minum kemasan galon. 


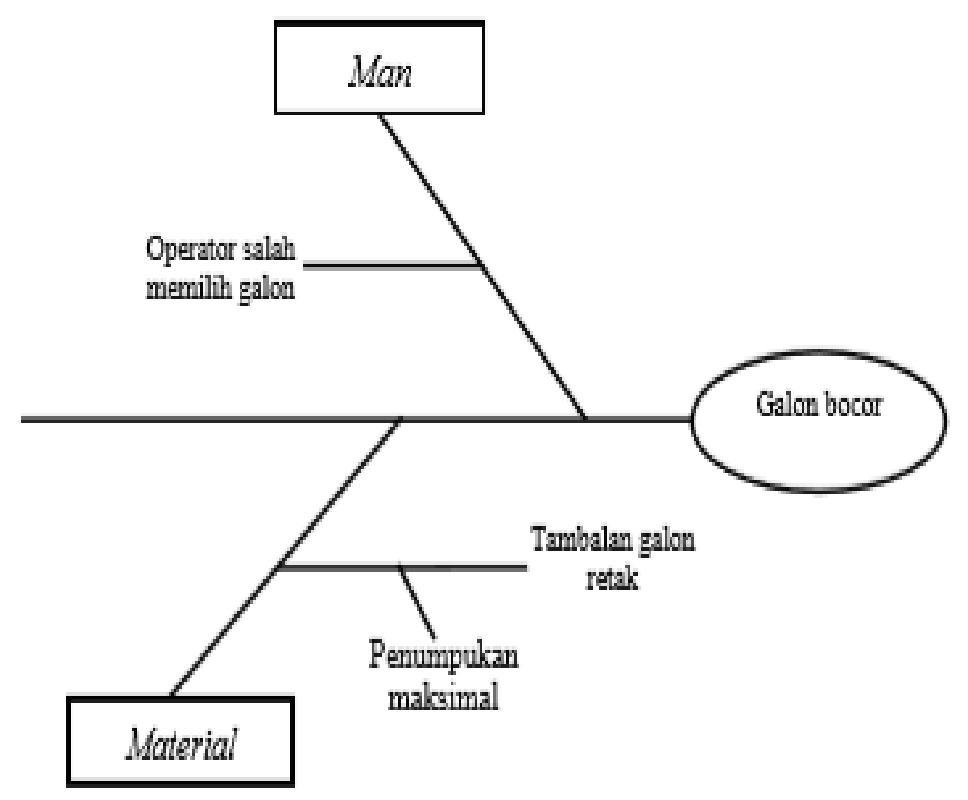

Gambar 3. Penyebab kecacatan galon bocor

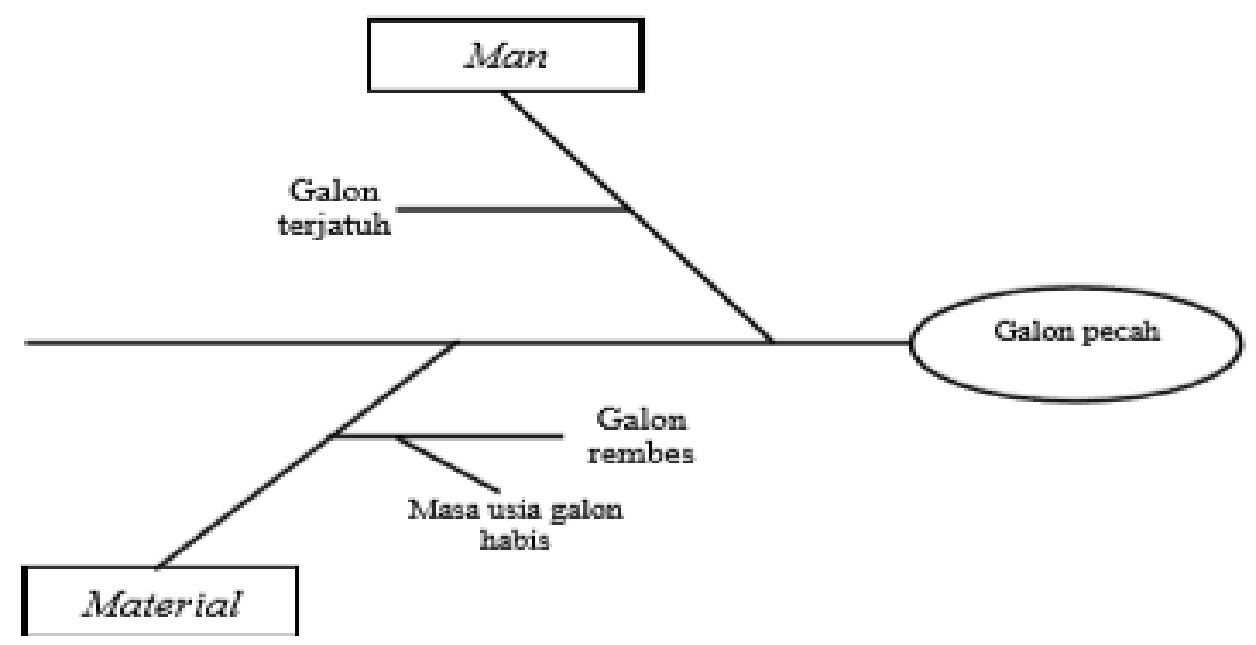

Gambar 4. Penyebab kecacatan galon pecah

\section{d. Improve}

Pada tahap ini akan dilakukan pemberian rencana tindakan perbaikan untuk meningkatkan kualitas. Berdasarkan identifikasi yang telah dilakukan, maka usulan perbaikan secara umum adalah pengecekan tidak hanya dengan dilihat tapi juga dengan menguji galon diisi dengan air serta. memberi tanda pada galon yang memiliki tambalan agar tidak tertukar pada saat penumpukkan galon untuk meminimalkan galon bocor. Usaha yang dapat dilakukan untuk mengurangi galon pecah adalah .saat melakukan pemilihan galon, hendaknya operator memperhatikan tahun galon untuk memastikan bahwa galon yang digunakan belum kadaluarsa.

\section{KESIMPULAN}

Berdasarkan pengolahan data yang telah dilakukan, maka dapat disimpulkan bahwa nilai DPMO rata-rata pada proses produksi air minum kemasan galon yaitu 662, 46 yang menunjukkan bahwa dari sejuta kesempatan yang ada akan terdapat 662, 46 kemungkinan kecacatan produk. Tingkat sigma yang dicapai yaitu sebesar 4,84 dengan faktor dominan kecacatan galon bocor dan pecah. Usulan perbaikan yang dapat dilakukan untuk mengurangi cacat tersebut adalah dengan pengecekan dengan memberi tanda pada galon yang memiliki tambalan agar tidak tertukar pada saat penumpukkan, dan saat melakukan pemilihan galon, hendaknya operator 
memperhatikan tahun galon untuk memastikan bahwa galon yang digunakan belum kadaluarsa.

\section{DAFTAR PUSTAKA}

Caesaron, D., \& Simatupang, S. Y. P. (2015). Implementasi pendekatan DMAIC untuk perbaikan proses produksi pipa PVC (studi kasus PT. Rusli Vinilon). Jurnal Metris, 16(2), 91-96.

Charles, V., Kumar, M., \& Suggu, S. (2013). Adapting Fuzzy Linguistic Servqual Model: A comparative analysis of bank services. Middle-East Journal of Scientific Research, 18(8), 1119-1132.

Fatma, N. F., \&Lestari. (2017). Peningkatan Kualitas Produk AX2 Goretex Dengan Metode Six Sigma di PT. Panarub Industry. Journal Industrial Manufacturing, 1, 50-57.

Gaspersz, V., (2002), Pedoman Implementasi Program Six Sigma Terintegrasi ISO 9001 : 2000, MBNQA Dan HACCP, PT. Gramedia Pustaka Utama, Jakarta

Ghiffari, I., Harsono, A., \& Bakar, A. (2013). Analisis Six Sigma untuk Mengurangi Jumlah Cacat di Stasiun Kerja Sablon (Studi Kasus: CV. Miracle). REKA INTEGRA, 1(1), 156-165

Pande, P. S., Neuman, R. P., \& Cavanagh, R. R. (2002). The Six Sigma Way-Bagaimana GE Motorola, dan Perusahaan Terkenal Lainnya Mengasah Kinerja Mereka. Yogyakarta: Andi

Prastawa, H., Khoiriyah, N., \& Sutarso, D. (2005). Penerapan Metode Peningkatan kualitas Six Sigma Guna Meningkatkan Kapabilitas Proses Dan Meminimasi Cacat Pada Produk Kain Denim Short No 9881 Di PT. Apac Inti Corpora. In Apac Inti Corpora, Prosiding Seminar Nasional II, Forum Komunikasi Teknik Industri, Jogjakarta.

Wibisono, Y. Y., \& Suteja, T. (2013). Implementasi Metode DMAIC-Six Sigma dalam Perbaikan Mutu di Industri Kecil Menengah: Studi Kasus Perbaikan Mutu Produk Spring Adjuster di PT. X, Prosiding Seminar Nasional IENACO

Widyarto, W. O., Dwiputra, G. A., \& Kristiantoro, Y. (2015). Penerapan Konsep Failure Mode and Effect Analysis (FMEA) dalam Pengendalian Kualitas Produk Dengan Menggunakan Metode Six Sigma. Jurnal Rekavasi, 3(1), 54-60. 